\title{
Evaluation of drought impact on groundwater recharge rate using SWAT and Hydrus models on an agricultural island in western Japan
}

\author{
G. Jin ${ }^{1}$, Y. Shimizu ${ }^{2}$, S. Onodera ${ }^{1}$, M. Saito ${ }^{3}$, and K. Matsumori ${ }^{2}$ \\ ${ }^{1}$ Graduate School of Integrated Arts and Sciences, Hiroshima University, Higashi-Hiroshima, Japan \\ ${ }^{2}$ WARC, National Agriculture and Food Research Organization, Fukuyama, Japan \\ ${ }^{3}$ Graduate School of Environmental and life Science, Okayama University, Okayama, Japan \\ Correspondence to: G. Jin (jinguangzhe@live.cn)
}

Received: 12 March 2015 - Accepted: 12 March 2015 - Published: 12 June 2015

\begin{abstract}
Clarifying the variations of groundwater recharge response to a changing non-stationary hydrological process is important for efficiently managing groundwater resources, particularly in regions with limited precipitation that face the risk of water shortage. However, the rate of aquifer recharge is difficult to evaluate in terms of large annual-variations and frequency of flood events. In our research, we attempt to simulate related groundwater recharge processes under variable climate conditions using the SWAT Model, and validate the groundwater recharge using the Hydrus Model. The results show that annual average groundwater recharge comprised approximately $33 \%$ of total precipitation, however, larger variation was found for groundwater recharge and surface runoff compared to evapotranspiration, which fluctuated with annual precipitation variations. The annual variation of groundwater resources is shown to be related to precipitation. In spatial variations, the upstream is the main surface water discharge area; the middle and downstream areas are the main groundwater recharge areas. Validation by the Hydrus Model shows that the estimated and simulated groundwater levels are consistent in our research area. The groundwater level shows a quick response to the groundwater recharge rate. The rainfall intensity had a great impact on the changes of the groundwater level. Consequently, it was estimated that large spatial and temporal variation of the groundwater recharge rate would be affected by precipitation uncertainty in future.
\end{abstract}

\section{Introduction}

Estimation of groundwater recharge, quantity, and water balance is important for efficiently managing groundwater resources. It is particularly important in regions with little rain, which face the risk of water shortage. However, the rate of aquifer recharge is one of the most difficult factors to evaluate. In fact, former methods of groundwater recharge estimation are normally subject to large uncertainties and easily cause errors (Kurylyk et al., 2013). Based on this issue, computer based hydrological models could provide an option for solving this complex problem.

The water balance of a watershed is sensitive to climate variability and change. Climate changes due to global warming may alter rainfall patterns and increase the occurrence of extreme events (floods and droughts), i.e., a change in the frequency and intensity of rainstorms (Nicholls and Hoozemans, 1996). This will increase the severity of droughts, and in past decades has caused variation and uncertainty of the regional water balance. Because climate change will significantly affect the sustainability of water supplies in the coming decades, understanding future water budgets will be necessary and important.

The Soil and Water Assessment Tool (SWAT) Model is a physically based and quasi-distributed continuous time hydrological model used to estimate water budgets in many studies around the world. The SWAT Model has been implemented in watershed hydrology related issues, such as estimation of surface water flow and groundwater recharge rate. The Hydrus Model is one of the models that can analyse wa- 

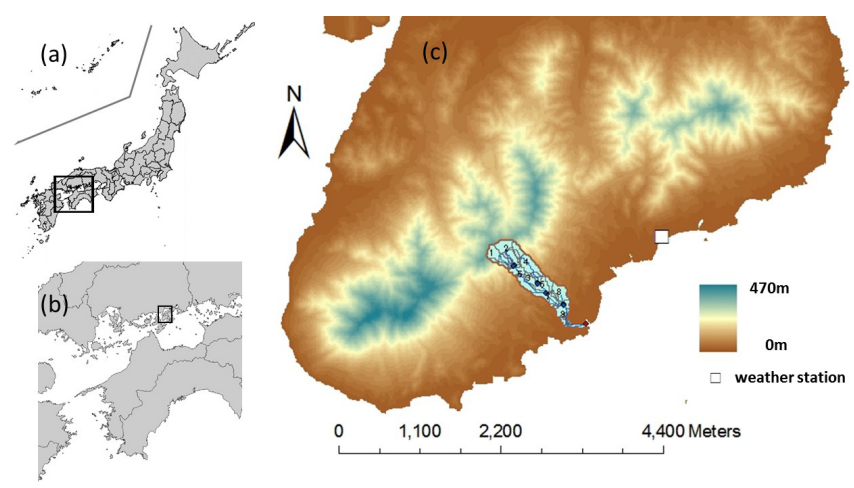

Figure 1. The research area in Japan (a), the Central Seto Inland Sea (b), research catchment (c).

ter flow and solute transport in two- and three-dimensional variably saturated media. Many researchers have used this model to simulate groundwater flow in agricultural fields. In this study, we simulate the groundwater flux by combining the SWAT and Hydrus Models. The objective of this research is to estimate water balance and clarify the groundwater recharge parameter on an island in the Seto Inland Sea using the SWAT Model, after that, we validate the groundwater recharge rate and estimate the groundwater movement using the Hydrus Model.

\section{Study area and methods}

\subsection{Study area}

Ikuchi Island $\left(34^{\circ} 16^{\prime} \mathrm{N}, 133^{\circ} 06^{\prime} \mathrm{E}\right)$ is located in the central Seto Inland Sea (Fig. 1). The regional climate is mild (average temperature of $15.6^{\circ} \mathrm{C}$ ), with little precipitation (approx. $1000 \mathrm{~mm} \mathrm{yr}^{-1}$ ). Ikuchi Island is one of the most famous and important orange production areas. Groundwater resources are important water supply resources for irrigation. However, due to the small annual precipitation with large inter-annual variation, and steep sloping topography, the island faces a risk of water shortage, especially in the drought season. The research catchment (IKS catchment) is located in the southern area of the island, and is approximately $1700 \mathrm{~m}$ in length and $300 \mathrm{~m}$ in width, with an area of $0.434 \mathrm{~km}^{2}$. The IKS catchment has a steep slope, particularly in the upstream mountainous area, with a top elevation of approximately $470 \mathrm{~m}$. The orange groves cover $42 \%$ of the total catchment area, and are mostly located in the downstream area. Forests cover $43 \%$ of the upper area. The main soil type of the IKS catchment is cambisols (64\% of the total catchment).

\subsection{Data preparation}

The input data of precipitation, temperature, wind speed, and relative humidity were obtained from recorded data
Table 1. Model performance ratings.

\begin{tabular}{lccccc}
\hline & NSE & RSR & PBIAS (\%) & $R^{2}$ & Number of days \\
\hline Calibration & 0.82 & 0.42 & -6.7 & 0.84 & 179 \\
Validation & 0.72 & 0.53 & 20.5 & 0.78 & 145 \\
\hline
\end{tabular}

from three weather stations at Ikuchijima, Fukuyama, and Takehara. Meteorological data were obtained from the Japan Meteorological Agency (JMA). Solar radiation data were obtained from the National Institute for AgroEnvironmental Sciences. Evaporation was estimated by the Penman-Monteith method using SWAT. As input to SWAT, topographic data (10 m grid), a soil map (1/25000), and a land use map of 2006 (100 m grid) were used to build and calculate the SWAT Model. Generated discharge outlets were calculated in the southern islands, and the observed surface runoff and groundwater variation data were used to calibrate and validate the model. The simulation time period was between the years 2000-2013, which included a model spinup period of 2000-2003 and calibration/validation period of 2003-2004.

For input into Hydrus 1-D, the groundwater recharge rate was obtained from the value in sub basin 9 in the SWAT model, the soil type was set according to the boring core in the downstream area in the catchment, and the simulation time period was set from 2008-2013, including the spinup period of 2008-2009 and the simulation period of January 2009-June 2013. The simulated groundwater level data were compared with observed groundwater level data from a $15 \mathrm{~m}$ depth observation well in the downstream area of the IKS catchment.

\subsection{Calibration and validation of the SWAT model}

The calibration was conducted using the method of Sequential Uncertainty Fitting version 2 (SUFI2) and SWAT-CUP version 5.1.6.2. The amount of groundwater recharge is calculated as the water discharge into the aquifer except the flows that are eventually discharged from aquifer, such as return flows into the river and the amount of water moving into the vadose zone. The total observation time period was divided into two parts: 179 days of calibration and 145 days of validation (Fig. 2). The calibration period for river runoff was set during the period from Mai-November 2003. The model reproducibility of discharge in the calibration period is shown in Table 1 . The calibration and validation results of Nash-Sutcliffe efficiency (NSE) (Nash and Sutcliffe, 1970), RMSE-observations standard deviation ratio (RSR), and percent bias (PBIAS) indicate "very good" and "good" performance ratings, respectively, for a monthly time step according to Moriasi et al. (2007). In our simulation, we follow the previous guideline and testified the groundwater recharge by Hydrus model. We set the time step to daily simulation, Based on these, the reproducibility of the model using cali- 


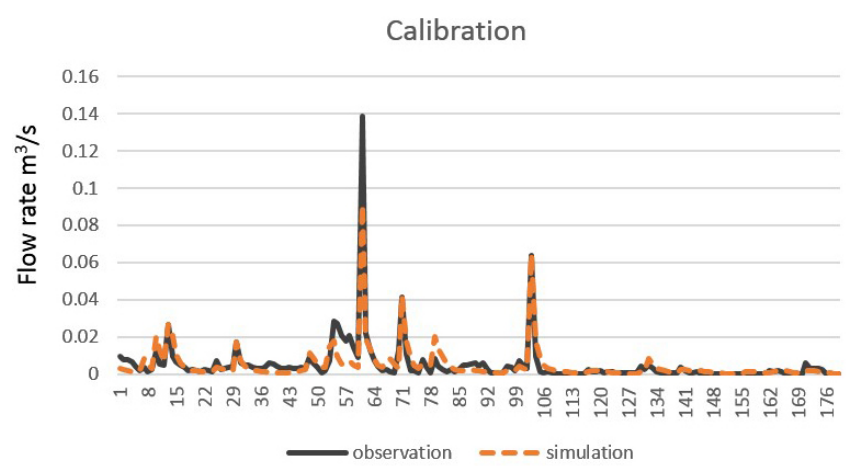

Validation

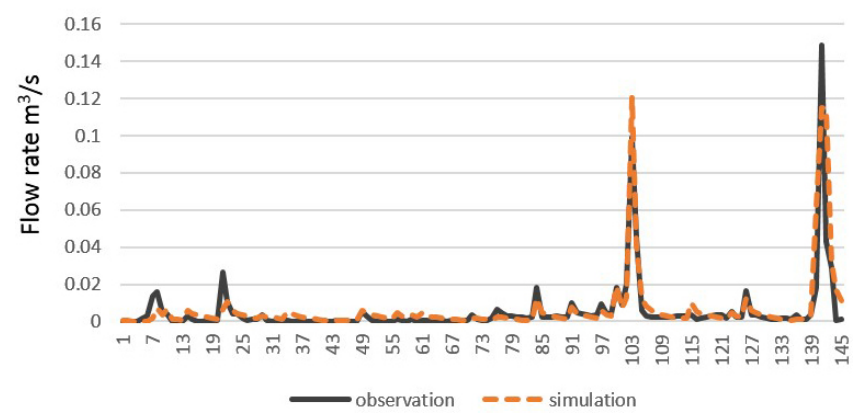

Figure 2. Calibration and validation curve of the river runoff in the IKS catchment.

brated parameters indicated the parameters are evaluated as acceptable.

\section{Results and discussion}

\subsection{Annual variation of groundwater recharge rate}

For the calibrated catchment, the annual variation of the water balance is shown in Fig. 3, there shows lower values in both surface runoff and groundwater recharge in the drought year. As an average value, groundwater recharge shows a relatively smaller value (it comprises approximately $33 \%$ of total precipitation in annual average consideration) than river discharge $(35 \%)$. In the low precipitation year, the groundwater recharge and surface runoff decreased to 25 and $30 \%$, respectively. Both river discharge and groundwater recharge fluctuated between the high and low precipitation years compared to average water balance (Fig. 3), and these variations are larger than the precipitation fluctuation. For example, the year 2005 was a dry year with precipitation of $781 \mathrm{~mm}$, which decreased $45 \%$ from 2004, however, the surface runoff and groundwater recharge decreased 59 and $55 \%$, respectively. The variation in evapotranspiration is relatively small (16\%). In addition, from 20112012, precipitation decreased $33 \%$, with relatively larger decreases in surface runoff and groundwater recharge (45 and $35 \%$, respectively). This indicates that the annual variation of groundwater resource supply is related to precipita-

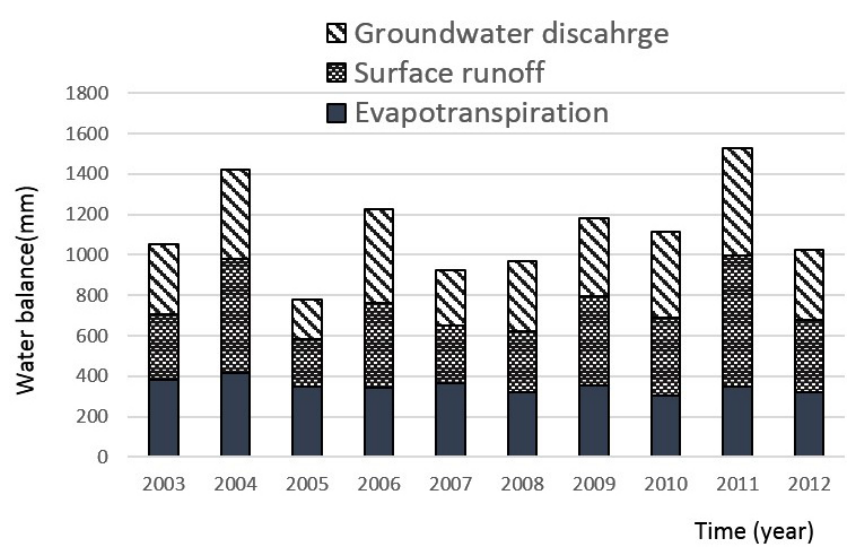

Figure 3. Annual variation of the water budget.

tion variations, and surface runoff and groundwater recharge show highly positive correlations to the precipitation (Fig. 4). As global climate change increases, water resource stress in locations where runoff and groundwater resources decrease, and droughts will become substantially more frequent (Arnell, 2004); these responses have been shown to be larger than variations in precipitation in this research catchment. The decreased precipitation may have a higher impact on the decrease in groundwater resources on a mountainous agricultural island, such as the research island.

The middle and downstream areas in the IKS catchment are considered to be the main groundwater recharge areas, whereas the upstream area is considered to be the main discharge area. This large difference in groundwater may be related to the topographic characteristics in the mountainous area. Groundwater recharge in mountain-plain transitional areas can contribute by both direct recharge of local precipitation and mountain-front recharge (Liu and Yamanaka, 2012). Because the slope will produce less groundwater recharge, especially under heavy rainfall situations (Wang et al., 2015), the large slopes with forest distribution in upper stream area will result in the small groundwater recharge rate in the upstream region. The reachrged groundwater will be considered discahrge into coastal sea by submarine groundwater discahrge process.

\subsection{Extreme drought impact on groundwater recharge rate}

Hydrus 1-D has been widely applied to simulate the water flow and nutrient movement in paddy fields (Tan et al., 2015). This has been demonstrated to be a useful method to simulate groundwater movement and water balance ( $\mathrm{Li}$ et al., 2014). We applied the simulated groundwater recharge rate obtained from the most downstream sub basin into Hydrus Model, there shows similarity between estimated and simulated groundwater levels in our research area (Fig. 5). Results show a quick response of the groundwater level to ground- 

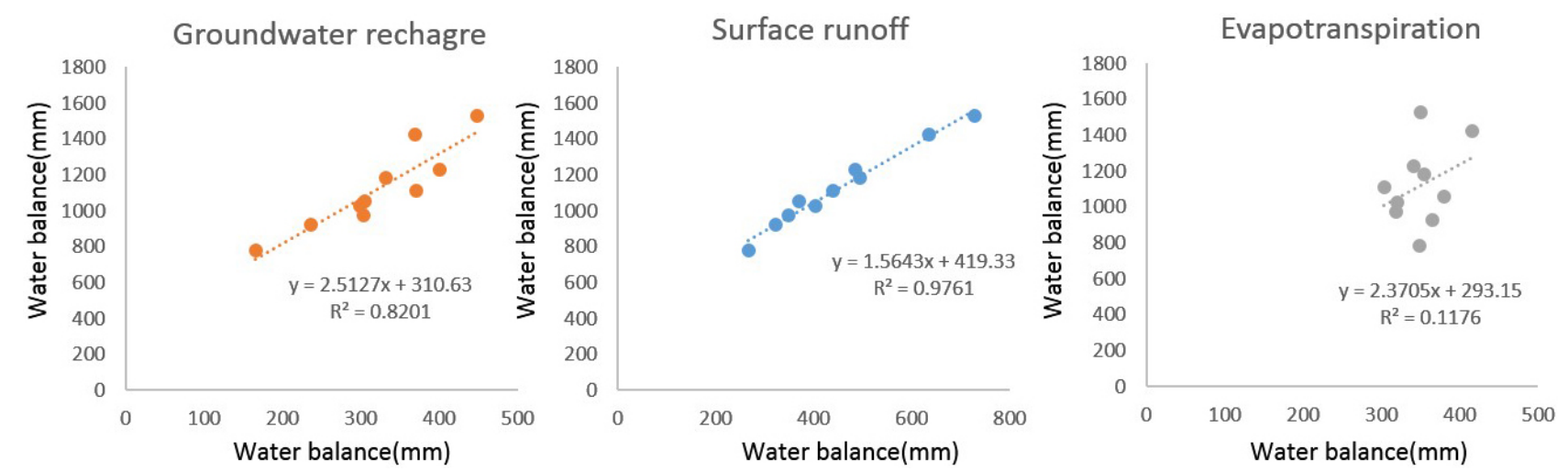

Figure 4. Relationship between precipitation and simulated evapotranspiration, surface runoff and groundwater recharge.

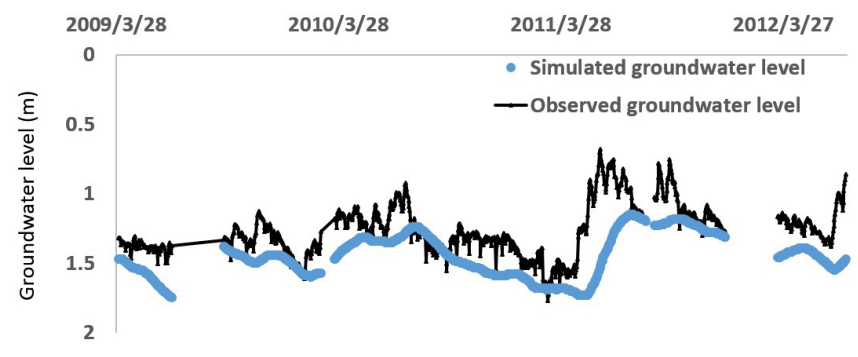

Figure 5. Simulated and estimated groundwater level.

water recharge rate changes, and little delay in the simulated groundwater level variation compared to observations. This is probably due to the limitation of the 1-D model, which can simulate vertical flow, but the horizontal flow from the hill to the coastal area would also contribute to the groundwater level change, and may accelerate the response of the water level in the recharge process. However, due to the depth of the observed well $(15 \mathrm{~m})$, the response would be relatively delayed compared to the relatively shallow observation well.

The simulated groundwater level data shows the quick response to variation of precipitation (Fig. 5). Groundwater levels for different rainfall intensities showed that groundwater levels gradually decreased and responded to the changes in groundwater recharge with no precipitation supplied. This indicates that the groundwater level was also highly related to precipitation variability. This is reflected in the difference between the drought and flood seasons, such as in the summer season of 2011, which showed the highest groundwater level among four years, and was related to high precipitation from five heavy rainfall events, three of which were within one month. This shows that the groundwater supply is highly related to heavy rainfall events and the obviously decreasing groundwater resources in the drought season. Climate change effects have been reported for the daily precipitation in Japan, including typhoons and extreme drought and flood events. The annual water budget has shown the impact from these large variations. These results indicate that rainfall intensity

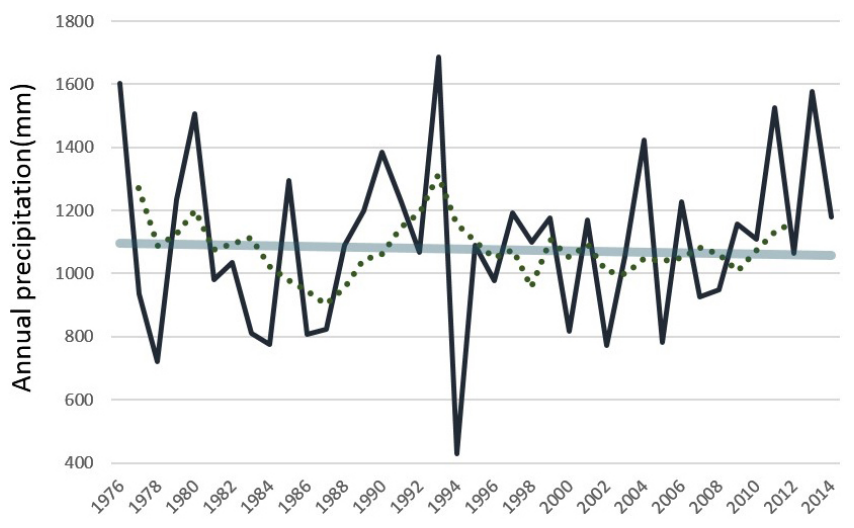

Figure 6. Annual variations and trend of 5 year average precipitation from 1976-2014.

also had a great impact on the changes of groundwater level. The groundwater resources will be accompanied with a high level of uncertainty due to seasonal or decadal climate and groundwater variations in the future.

\subsection{Future drought impact on groundwater resources}

As result of global climate change, the average annual surface air temperature has increased over the past few decades. An increasing fluctuation trend between extremely low rainfall and extremely high rainfall has been observed across Japan (Yue and Hoshino, 2003). In addition to the abovementioned decrease in precipitation and frequent occurrence of extreme drought years, Fig. 6 shows the annual precipitation from the Ikuchi Island weather station for the past 38 years, which suggests that years of low rainfall have become more frequent since 1976, and the amount of precipitation was substantially below average in 1977-1978, 1983-1984, 1986-1987, and 1994, when groundwater shortages caused damage. Base on that estimation, a decreasing trend of precipitation from 5-year average data is shown in research area,

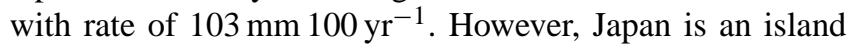




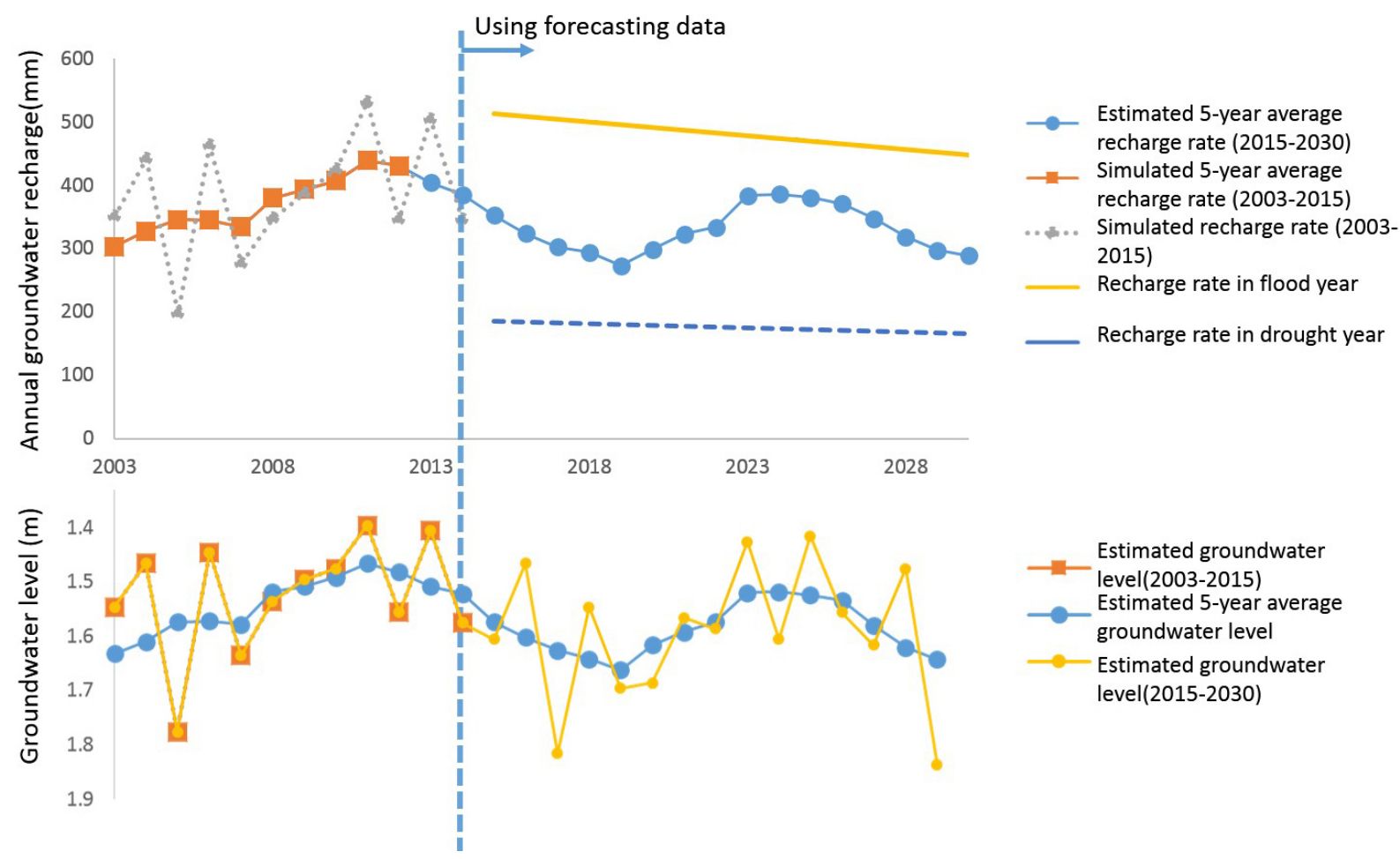

Figure 7. Estimated trend of groundwater recharge rate and groundwater level.

country with frequent typhoons, the estimation of precipitation trend in Japan is difficult with spatial uncertainty. Generally, there is a decreasing tendency in annual precipitation during the past century in research area (Xu et al., 2003). In consideration of this decreasing trend in precipitation, we estimate the future impact of decreasing precipitation trend under similar intervals of drought periods in 2003-2014. The results in Fig. 7 show that the estimated annual groundwater recharge rate had considerable inter-annual variations and decreased on an average by $140 \mathrm{~mm} 100 \mathrm{yr}^{-1}$, which is relatively larger than the trend of precipitation. This may indicate the drought impact on groundwater resources will increase in the future. The climate change effect will amplified in the recharge rate variation. Although the groundwater supply is highly related to heavy rainfall events in research watershed, the general view of groundwater resources will be considered more obviously relate to decreasing precipitation in the drought season. In simulation, the groundwater recharge will decrease in long term average (Fig. 7). Because the estimated recharge rate was used as input into Hydrus 1-D, the groundwater level in drought years decreased in the same way, with

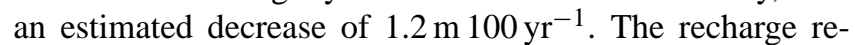
sources will decrease and groundwater storage will decline under the trend of decreasing precipitation in the future.

\section{Conclusions}

This research aimed to estimate water balance and clarify the groundwater recharge parameter in the IKS catchment using the SWAT Model, and validate and estimate the groundwater using the Hydrus Model, to evaluate the possible impact of drought and rainfall events on groundwater recharge to better manage groundwater resources. The results showed that annual average groundwater recharge comprises approximately $33 \%$ of total precipitation; however, the results indicated larger variations of surface runoff and groundwater recharge compare to precipitation between the high and low precipitation years. In terms of the spatial variations of the groundwater recharge rate, the upstream is the main surface water discharge area, whereas the middle and downstream areas are the main groundwater recharge areas. The estimated and simulated groundwater levels were consistent in our research area. The groundwater level responds quickly to changes in the groundwater recharge rate. It was estimated that the large spatial and temporal variation of the groundwater recharge rate would be affected by precipitation uncertainty in the future. However, it is noted that Hydrus 1-D has some limitations in estimating the horizontal flow, which may include some uncertainty and cause delayed prediction of groundwater level. Therefore, future work should improve and better merge these two different kinds of hydrological models. 
Acknowledgements. This work was supported by JSPS KAKENHI Grant no. 25241028.

\section{References}

Arnell, N. W.: Climate change and global water resources: SRES emissions and socio-economic scenarios, Glob. Environ. Chang., 14, 31-52, 2004.

Kurylyk, B. L. and MacQuarrie, K. T. B.: The uncertainty associated with estimating future groundwater recharge: A summary of recent research and an example from a small unconfined aquifer in a northern humid-continental climate, J. Hydrol., 492, 244 253, 2013.

Li, Y., Šimůnekc, J., Jing, L., Zhang, Z., and Ni, L.: Evaluation of water movement and water losses in a direct-seeded-rice field experiment using Hydrus-1-D, Agric. Water Manage., 142, 3846, 2014.

Liu, Y. and Yamanaka, T.: Tracing groundwater recharge sources in a mountain-plain transitional area using stable isotopes and hydrochemistry, J. Hydrol., 464/465, 116-126, 2012.
Moriasi, D. N., Arnold, J. G., Van Liew, M. W., Bingner, R. L., Harmel, R. D., and Veith, T. L.: Model evaluation guidelines for systematic quantification of accuracy in watershed simulations, T. ASABE, 50, 885-900, 2007.

Nash, J. E. and Sutcliffe, J. V.: River flow forecasting through conceptual models, Part I - A discussion of principles, J. Hydrol., 10, 282-290, 1970.

Nicholls, R. J. and Hoozemans, F. M. J.: The Mediterranean: vulnerability to coastal implications of climate change, Ocean Coast. Manage., 31, 105-132, 1996.

Tan, X., Shao, D., Gu, W., and Liu, H.: Field analysis of water and nitrogen fate in lowland paddy fields under different water managements using HYDRUS-1-D, Agric. Water Manage., 150, 6780, 2015.

Wang, H., Gao, J., Zhang, M., Li, X., Zhang, S., and Jia, L.: Effects of rainfall intensity on groundwater recharge based on simulated rainfall experiments and a groundwater flow model, Catena, 127, 80-91, 2015.

Xu, Z. X., Takeuchi, K., and Ishidaira, H.: Monotonic trend and step changes in Japanese precipitation, J. Hydrol., 279, 144-150, 2003.

Yue, S. and Hashino, M.: Long term trends of annual and monthly precipitation in Japan 1, J. Am. Water Resour. Assoc., 39, $587-$ 596, 2003. 